\title{
Article
}

\section{Low-Temperature Growth of Axial Si/Ge Nanowire Heterostructures Enabled by Trisilane}

Ho Yee Hui, María de la Mata, Jordi Arbiol, and Michael A Filler

Chem. Mater., Just Accepted Manuscript • DOI: 10.1021/acs.chemmater.6b03952 • Publication Date (Web): 19 Mar 2017

Downloaded from http://pubs.acs.org on March 19, 2017

\section{Just Accepted}

"Just Accepted" manuscripts have been peer-reviewed and accepted for publication. They are posted online prior to technical editing, formatting for publication and author proofing. The American Chemical Society provides "Just Accepted" as a free service to the research community to expedite the dissemination of scientific material as soon as possible after acceptance. "Just Accepted" manuscripts appear in full in PDF format accompanied by an HTML abstract. "Just Accepted" manuscripts have been fully peer reviewed, but should not be considered the official version of record. They are accessible to all readers and citable by the Digital Object Identifier (DOI®). "Just Accepted" is an optional service offered to authors. Therefore, the "Just Accepted" Web site may not include all articles that will be published in the journal. After a manuscript is technically edited and formatted, it will be removed from the "Just Accepted" Web site and published as an ASAP article. Note that technical editing may introduce minor changes to the manuscript text and/or graphics which could affect content, and all legal disclaimers and ethical guidelines that apply to the journal pertain. ACS cannot be held responsible for errors or consequences arising from the use of information contained in these "Just Accepted" manuscripts.

\section{ACS Publications}


Control of composition at the nanoscale is central to the construction and operation of devices ranging from field effect transistors to solar cells. ${ }^{1-2}$ It is also critical for advanced materials where the arrangement of nanoscale constituent elements gives rise to exotic properties. ${ }^{3-5}$ The vapor-liquid-solid (VLS) mechanism, which permits the encoding of different materials and/or compositions along the length of semiconductor nanowires, provides one route to programmable compositional heterogeneity. ${ }^{6-9}$ Group III-V nanowires, due to the low solubility of group $\mathrm{V}$ atoms in the catalyst droplet and the wide parameter space offered by the use of two precursors (i.e., for delivering group III and $\mathrm{V}$ atoms), currently offer the best control of axial heterostructure. Axially embedded quantum dots can be fabricated with heights ranging from one to several bilayers. ${ }^{10-11}$

Axial heterostructure formation remains challenging for group IV nanowires. ${ }^{12}$ Yet, the promise of these heterostructures in applications such as transistors ${ }^{13-15}$ for large-area integrated circuits and thermoelectrics ${ }^{16-18}$, where low cost, low toxicity, and thermal stability are paramount, continues to motivate work in this area. To date, the large majority of axial $\mathrm{Si} / \mathrm{Ge}$ heterostructure nanowire syntheses yield non-ideal structural motifs including diameter changes, ${ }^{19-20}$ sidewall deposition, ${ }^{9,21}$ kinking, ${ }^{82-23}$ and/or crystallographic defects. ${ }^{22}$ $\mathrm{Si} / \mathrm{Ge}$ heterostructure nanowires without these unwanted structural motifs are possible, but with growth rates usually too rapid to encode highly confined structures. ${ }^{24-25}$ In many cases, co-flow of a second precursor, such as $\mathrm{HCl}$, is also necessary to improve sidewall morphology. ${ }^{26-27}$ This approach, however, requires careful control of growth conditions to prevent surface roughening from halogen-induced surface atom removal (e.g., as $\mathrm{SiX}_{2}$ or $\mathrm{GeX}_{2}$ where $\mathrm{X}=\mathrm{Cl}$ or $\mathrm{Br}$ ). ${ }^{28-30}$ A notable exception to the above challenges is vapor-solid-solid (VSS) growth with an alloyed catalyst (e.g., $\mathrm{Au} / \mathrm{Al}, \mathrm{Au} / \mathrm{Ag}$ ), which is able to produce sub-5 $\mathrm{nm}$ Ge domains along the length of $\mathrm{Si}$ nanowires. $^{31-32}$

Here, we demonstrate arrays of axial $\mathrm{Si} / \mathrm{Ge}$ heterostructure nanowires with excellent sidewall morphologies and purely axial composition profiles. We use the precursors trisilane $\left(\mathrm{Si}_{3} \mathrm{H}_{8}\right)$ and digermane $\left(\mathrm{Ge}_{2} \mathrm{H}_{6}\right)$ for $\mathrm{Si}$ and $\mathrm{Ge}$ segment growth, respectively, with a conventional Au catalyst. Trisilane is highly reactive, enabling Si homoepitaxy as low as $300{ }^{\circ} \mathrm{C} .{ }^{33}$ This precursor choice is motivated by the reduced $\mathrm{H}_{2}$ desorption rate on both $\mathrm{Si}^{34-35}$ and $\mathrm{Ge}^{36-37}$ surfaces at these temperatures. The nanowire sidewalls are expected to remain largely hydrogen-passivated during $\mathrm{Si} / \mathrm{Ge}$ heterostructure formation, and limit the catalyst perturbations that can lead to poor morphologies, kinking, and defects. This approach also offers growth rates slow enough for quantum dot and/or superlattice fabrication.

METHODS. All nanowires are synthesized in a custom-built ultra-high vacuum (UHV) chamber with a base pressure of $3 \times$ $10^{-10}$ Torr (McAllister Technical Services). A description of the chamber and substrate preparation methods are included in prior studies. ${ }^{38-39}$ Briefly, substrates are cut into rectangles (6 $\mathrm{mm} \times 24 \mathrm{~mm}$ ) from a double-side polished $\mathrm{Ge}(111)$ wafer (MTI Corp., CZ, $500 \mu \mathrm{m}, 42-64 \Omega$-cm). Each substrate is repeatedly oxidized in $3 \mathrm{wt} \% \mathrm{H}_{2} \mathrm{O}_{2}$ (JT Baker, $30 \mathrm{wt} \%$, ACS grade), etched with $9 \mathrm{wt} \% \mathrm{HCl}$ (JT Baker, CMOS grade), cleaned with dionized water, and dried with $\mathrm{N}_{2}$ gas. The substrate is then immersed in a 1:2:20 $\mathrm{NH}_{4} \mathrm{OH}$ (Sigma-Aldrich, $28-30 \mathrm{wt} \%$, ACS grade) $: \mathrm{H}_{2} \mathrm{O}_{2}: \mathrm{H}_{2} \mathrm{O}$ solution, rinsed with dionized water, and dried with $\mathrm{N} 2$ gas. Upon insertion into the UHV chamber, the substrate is heated to $485^{\circ} \mathrm{C}$ to desorb the chemical oxide from the wet chemical treatment, followed by epitaxial Ge film deposition at $305{ }^{\circ} \mathrm{C}$ with a $\mathrm{Ge}_{2} \mathrm{H}_{6}$ (Air 
Liquide, $20 \%$ in He) partial pressure of $2 \times 10^{-5}$ Torr. Finally, a thin layer of $\mathrm{Au}(<0.5 \mathrm{~nm})$ is deposited onto the substrate at room temperature via thermal evaporation (SVT Associates). The substrate temperature is monitored throughout the nanowire growth by a calibrated infrared pyrometer (Mikron) focused on the backside of the substrate.

Nanowire growth begins with the same procedure utilized in a recent study. ${ }^{37}$ Briefly, $\mathrm{Ge}_{2} \mathrm{H}_{6}$ at a partial pressure of $1 \times 10^{-4}$ Torr is introduced to the chamber with the substrate at room temperature. The substrate is then heated to $485^{\circ} \mathrm{C}$ at a rate of $10{ }^{\circ} \mathrm{C} / \mathrm{s}$, held for $30 \mathrm{~s}$, and cooled to $305^{\circ} \mathrm{C}$ at a rate of $3{ }^{\circ} \mathrm{C} / \mathrm{s}$. A short Ge nanowire "stub" results from growth at these conditions for $5 \mathrm{~min}$. While maintaining the $\mathrm{Ge}_{2} \mathrm{H}_{6}$ partial pressure, the substrate temperature is lowered to $290{ }^{\circ} \mathrm{C}$ and the remainder of the $\mathrm{Ge}$ segment is grown over the course of 30 min. Si segment growth is initiated by flowing $\mathrm{Si}_{3} \mathrm{H}_{8}$ followed by termination of $\mathrm{Ge}_{2} \mathrm{H}_{6}$ flow. The $\mathrm{Si}$ segment is elongated at either 290,310 , or $330{ }^{\circ} \mathrm{C}$ with a $\mathrm{Si}_{3} \mathrm{H}_{8}$ (Air Liquide, $99.99 \%$ ) partial pressure of $1 \times 10^{-4}$ Torr for $30 \mathrm{~min}$. For Ge/Si/Ge heterostructures growth, $\mathrm{Ge}_{2} \mathrm{H}_{6}$ is re-introduced at a partial pressure of $1 \times 10^{-4}$ Torr prior to termination of $\mathrm{Si}_{3} \mathrm{H}_{8}$ flow. All segments of $\mathrm{Ge} / \mathrm{Si} / \mathrm{Ge}$ nanowires are synthesized at $290{ }^{\circ} \mathrm{C}$. Growth is terminated by rapidly reducing substrate temperature, after which all precursors are evacuated from the chamber.

Nanowire structure is analyzed with a Hitachi SU-8230 scanning electron microscopy (SEM) and a FEI Tecnai F20 transmission electron microscope (TEM). For TEM measurements, nanowires are transferred to carbon-coated grids (Ted Pella) by a direct mechanical transfer method. ${ }^{40}$ High resolution TEM (HRTEM) images are obtained with a $0.19 \mathrm{~nm}$ point-to-point resolution at $200 \mathrm{keV}$. For the compositional maps and profiles, we combine scanning TEM (STEM) with electron energy loss spectroscopy (EELS) in the same FEI Tecnai F20. An embedded Gatan image filter is used for EELS analyses. EELS can provide atomic-level spatial resolution for sufficiently thin samples. ${ }^{41}$ For nanowires with diameters similar to those studied here, typical signal broadening at heterointerfaces is less than $2 \mathrm{~nm}$. Heterointerfacial strain is analyzed by the geometric phase analysis (GPA) method. ${ }^{42}$ The GPA algorithm performs an analysis based on the amplitude and phase of the lattice fringes as a function of position in the HRTEM images at different Bragg reflection angles. A cosine type mask with the radius previously optimized is employed around the (1 -1 -1) growth plane for all nanowires.

RESULTS \& DISCUSSION. Figures $1 \mathrm{a}$ and $1 \mathrm{~b}$ show representative SEM images of $\mathrm{Si} / \mathrm{Ge}$ nanowire arrays where the $\mathrm{Si}$ segment is grown at 290 and $330{ }^{\circ} \mathrm{C}$, respectively. Si segment growth at $310{ }^{\circ} \mathrm{C}$ yields a similar morphology (Supporting Information, Figure S1). Nanowire morphology and crossarray uniformity is excellent ( $>98 \%$ verticality) for all temperatures (Supporting Information, Figure S2). Nanowires exhibit an epitaxial orientation relative to the Ge(111) substrate, indicating their growth is in the $<111>$ direction. As anticipated for a $\mathrm{Si} / \mathrm{Ge}$ heterostructure, the images in the Figure $1 \mathrm{a}$ and $1 \mathrm{~b}$ insets show a bright segment $(\mathrm{Ge})$ below a dark (Si) segment. The heterostructure forms properly in almost every nanowire. The growth rate of the initial Ge segment is $\sim 10.6 \mathrm{~nm} / \mathrm{min}$, as expected for growth at $290{ }^{\circ} \mathrm{C}$. ${ }^{39}$ The $\mathrm{Si}$ segment growth rate is far lower at $\sim 0.45,0.96$, and 1.64 $\mathrm{nm} / \mathrm{min}$ for 290,310 , and $330^{\circ} \mathrm{C}$, respectively.
Detailed structural analysis confirms the single-crystallinity and growth direction of the $\mathrm{Si} / \mathrm{Ge}$ heterostructure nanowires. Figure $2 \mathrm{a}$ shows a representative bright field TEM image of the near-catalyst region of a $\mathrm{Si} / \mathrm{Ge}$ heterostructure nanowire with Si segment growth at $290{ }^{\circ} \mathrm{C}$. Lattice fringes are clearly visible, demonstrating that the nanowire remains singlecrystalline across the $\mathrm{Si} / \mathrm{Ge}$ heterointerface. Figures $2 \mathrm{~b}, \mathrm{c}$ and 2d,e show high resolution TEM (HRTEM) images along the [1-12] zone axis and associated Fast Fourier Transform (FFT) for the nominally $\mathrm{Si}$ (blue box) and Ge (red box) segments, respectively. Both segments grow along the $<111>$ direction.
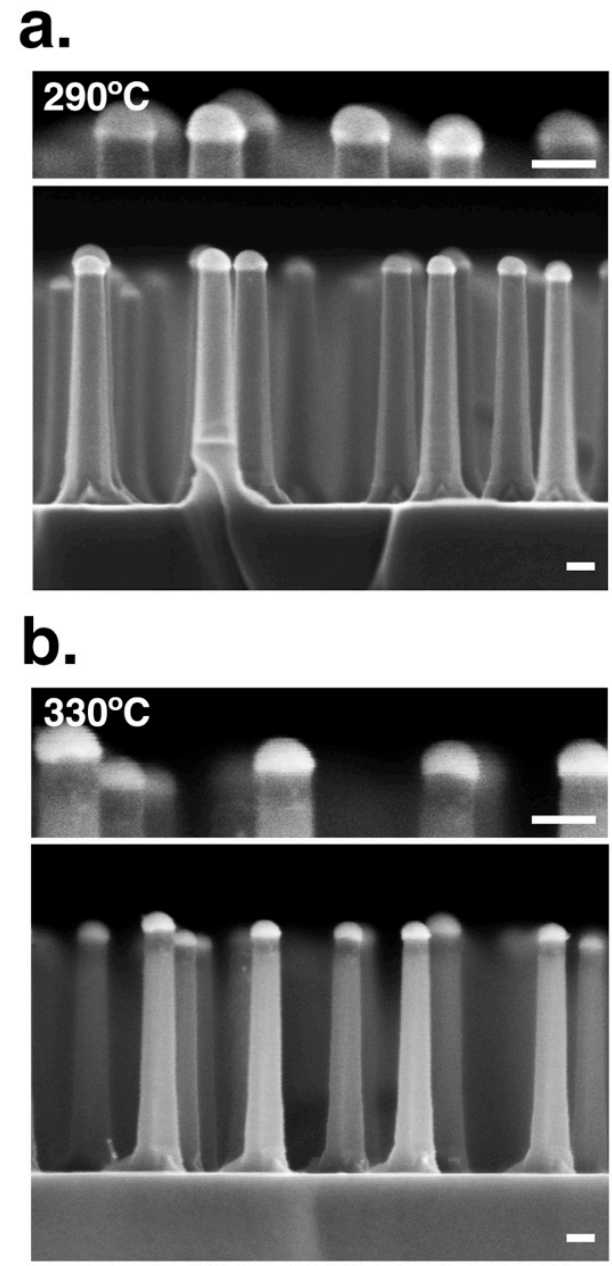

Figure 1. Representative cross-sectional SEM images of $\mathrm{Si} / \mathrm{Ge}$ heterostructure nanowires where the $\mathrm{Si}$ segment is grown at (a) $290{ }^{\circ} \mathrm{C}$ and (b) $330{ }^{\circ} \mathrm{C}$ for 30 minutes. Scale bars, $50 \mathrm{~nm}$.

Electron energy loss spectroscopy (EELS) measurements confirm the chemical identity of the Si and Ge segments. Figure 3 a shows a representative high angle annular dark field STEM (HAADF-STEM) image of a nanowire containing $\mathrm{Si} / \mathrm{Ge}$ nanowires with the $\mathrm{Si}$ segment grown at $290^{\circ} \mathrm{C}$. A contrast change near the catalyst is observed similar to that seen in Figure 1. As would be expected for hydrogen-passivated sidewalls, ${ }^{43}$ gold is only observed in the catalyst region. EELS maps of Si (blue) and Ge (red) are also shown in Figure 3a and definitively confirm the presence of $\mathrm{Si}$ and $\mathrm{Ge}$ segments. The top of each map is the liquid-solid interface.

The $\mathrm{Si} / \mathrm{Ge}$ heterointerface is compositionally graded along the axial direction, as seen in Figure $3 b$, for all temperatures 
studied here. A transition width of approximately 20 and 35 $\mathrm{nm}$ is observed for Si segment growth at 290 and $330^{\circ} \mathrm{C}$, respectively, and is considerably less than the nanowire diameter. $^{24-25}$ We discuss the observed compositional grading in more detail below. In addition, the absence of $\mathrm{Si}$ on the sidewall of the Ge -segment (Supporting Information, Figure S3) confirms that the heterostructure exhibits a purely axial composition profile. This observation provides additional support that the sidewall is well passivated.

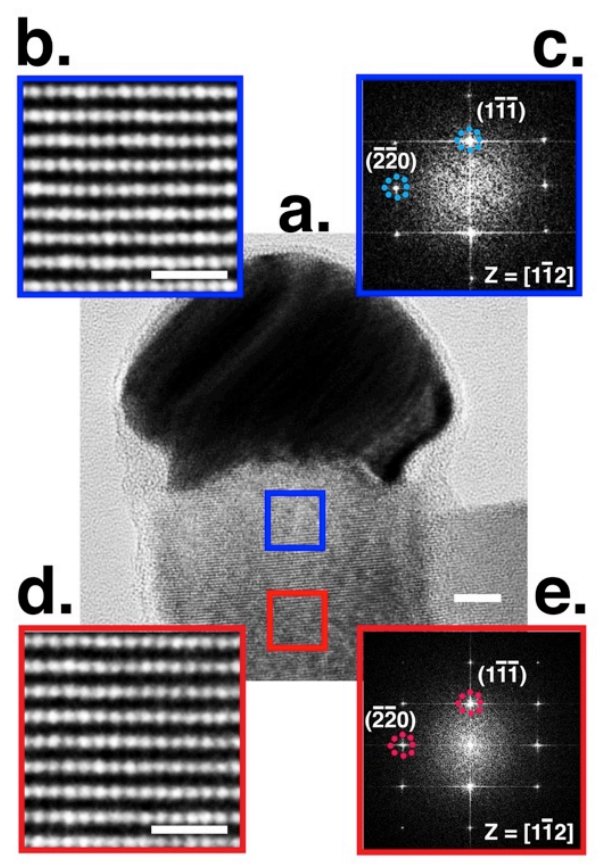

Figure 2. HRTEM of the $\mathrm{Si} / \mathrm{Ge}$ heterointerface. (a) HRTEM image of a nanowire with the $\mathrm{Si}$ and Ge segments grown at $290{ }^{\circ} \mathrm{C}$. Scale bar, $5 \mathrm{~nm}$. (b) High resolution TEM image of the Si segment. Scale bar, $1 \mathrm{~nm}$. (c) FFT of the image in (b) showing growth along the $<111>$ direction. (d) High resolution TEM image of the Ge segment. Scale bar, $1 \mathrm{~nm}$. (e) FFT of the image in (d) showing growth along the $<111>$ direction.

We quantify heterointerfacial strain, as shown in Figure 4, by combining HRTEM with geometric phase analysis (GPA). A transition region (green) between the Ge (red) and Si (blue) regions is clearly observed in the GPA maps. This transition is consistent with the axial compositional grading seen in the EELS data (Figure 3) and is analogous to recent reports for axial III-V heterostructures. ${ }^{44-45}$ The lattice mismatch is calculated to be $-3.7 \%$ and $-3.9 \%$ for Si segment growth at 290 and $330{ }^{\circ} \mathrm{C}$, respectively, which is close to that expected for an ideally relaxed bulk $\mathrm{Si} / \mathrm{Ge}$ heterointerface (approximately $4.0 \%$ ). We attribute the larger deviation from ideality for $\mathrm{Si}$ segment growth at $290{ }^{\circ} \mathrm{C}(-3.7$ vs. $-4.0 \%)$ to the length of the $\mathrm{Si}$ segment, which is shorter and thus remains more strained than the $\mathrm{Si}$ segment grown at $330^{\circ} \mathrm{C}(-3.9$ vs. $-4.0 \%)$. a.
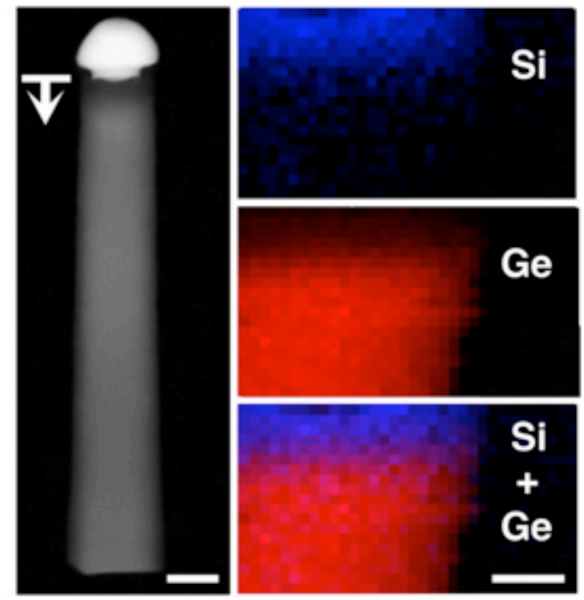

b.

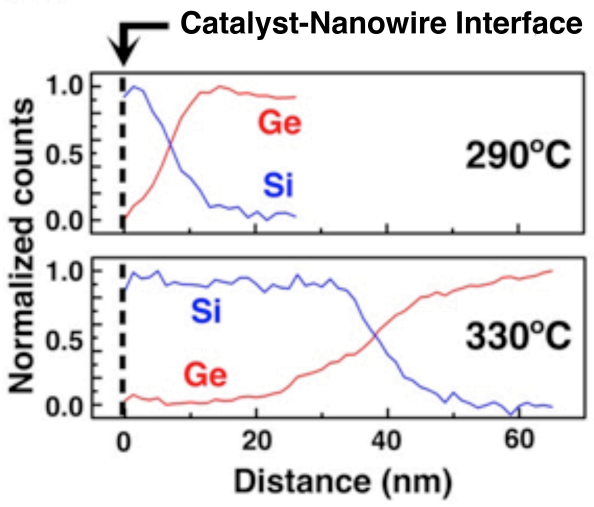

Figure 3. Compositional analysis of the $\mathrm{Si} / \mathrm{Ge}$ heterointerface. (a) Representative HAADF STEM image of a Si/Ge heterostructure nanowire grown entirely at $290{ }^{\circ} \mathrm{C}$. Scale bar, $30 \mathrm{~nm}$. White line denotes the liquid-solid interface. EELS maps of $\mathrm{Si}, \mathrm{Ge}$, and composite $\mathrm{Si}+\mathrm{Ge}$ are also shown. Scale bar, $10 \mathrm{~nm}$. (b) Axial EELS composition profiles starting at the catalyst-nanowire interface and crossing the $\mathrm{Si} / \mathrm{Ge}$ heterointerface for nanowires with the $\mathrm{Si}$ segment grown at 290 and $330^{\circ} \mathrm{C}$.

Nanowires containing $\mathrm{Ge} / \mathrm{Si} / \mathrm{Ge}$ heterostructures are also synthesized as shown in Figure 5. All segments are grown at $290{ }^{\circ} \mathrm{C}$ for $30 \mathrm{~min}$. A HAADF STEM image and the corresponding EELS composition map is displayed Figure 5a. A distinct Si segment is visible between two Ge segments, which confirms that Si crystallization is occurring under growth conditions. The HRTEM image in Figure 5b shows that the nanowire remains single-crystalline across both heterostructures. The EELS composition profile in Figure 5c, similar to Figure $3 b$, shows how the initially grown $\mathrm{Si} / \mathrm{Ge}$ heterointerface exhibits a graded composition. Interestingly, the subsequently grown heterointerface is more abrupt.

Our data show that the use of a $\mathrm{Si}_{3} \mathrm{H}_{8}$ and $\mathrm{Ge}_{2} \mathrm{H}_{6}$ chemistry solves many, but not all, of the challenges of conventional hydrides for $\mathrm{Si} / \mathrm{Ge}$ heterostructure formation. Foremost, the near-unity fraction of nanowires containing $\mathrm{Si} / \mathrm{Ge}$ heterostructures without kinks or defects (Figures 1, S1, S2), as well as the absence of radial composition grading (Figure S3), supports the presence of a robust, likely hydrogen, sidewall passivation. Additional studies are required to definitively 


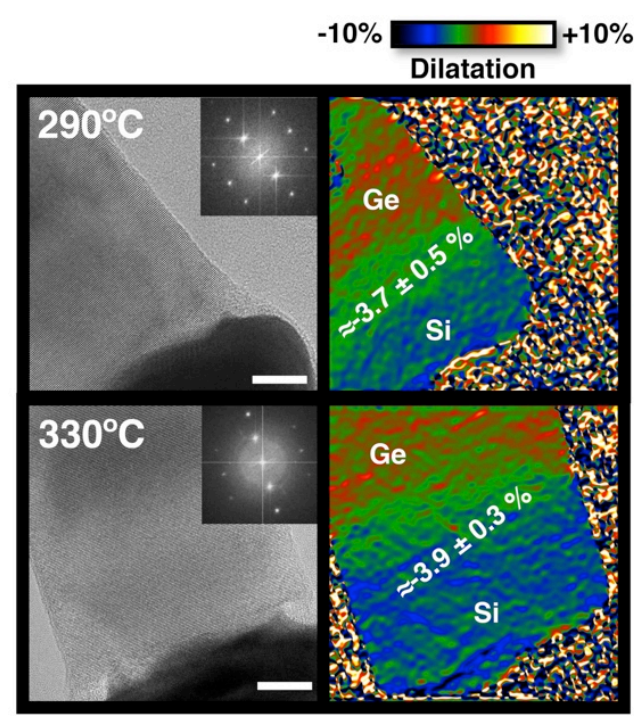

Figure 4. Strain analysis of the $\mathrm{Si} / \mathrm{Ge}$ heterointerface. HAADF STEM images of representative $\mathrm{Si} / \mathrm{Ge}$ heterostructure nanowires with the $\mathrm{Si}$ segment grown at $290{ }^{\circ} \mathrm{C}$ (left, top) and $330{ }^{\circ} \mathrm{C}$ (left, bottom). Scale bars, $10 \mathrm{~nm}$. Dilatation maps after applying GPA to the (1 -1 -1) $\mathrm{Si}$ and Ge growth planes for Si segment growth at $290{ }^{\circ} \mathrm{C}$ (right, top) and $330{ }^{\circ} \mathrm{C}$ (right, bottom). The GPA color scale ranges from -10 to $+10 \%$ lattice expansion.

identify the catalyst's phase during Ge to $\mathrm{Si}$ and $\mathrm{Si}$ to Ge transitions, but the present data provides important clues. The slow growth rate of the second Ge segment, especially relative to the first Ge segment (i.e., $\sim 0.5$ vs. $\sim 10 \mathrm{~nm} / \mathrm{min}$ ), indicates that the catalyst solidified during or prior to the $\mathrm{Si}$ to $\mathrm{Ge}$ transition. ${ }^{49}$ The low solubility of semiconductor atoms in solid catalysts also results in more abrupt heterointerfaces, ${ }^{32}$ as seen here for the Si to Ge transition. The larger composition grading observed for the Ge to Si transition, however, suggests that the catalyst was still liquid at that point during growth. Graded composition profiles are commonly observed for axial heterointerfaces synthesized with the VLS mechanism and attributed to the so-called "reservoir effect". ${ }^{46-47}$ While not as widely studied as Ge nanowire growth via the VLS growth mechanism below the bulk eutectic temperature, ${ }^{39,48-49} \mathrm{Si}$ nanowires have also been reported to grow via this mode.50 The presence of a liquid catalyst droplet for Si nanowire growth below the bulk eutectic temperature is supported by prior studies of Ge nanowire growth by $\mathrm{us}^{43}$ and others. ${ }^{49}$ In particular, we recently showed that hydrogen-passivated sidewalls maintain $\mathrm{Au} / \mathrm{Ge}$ catalysts in a metastable liquid state below the bulk eutectic temperature. ${ }^{43} \mathrm{~A}$ similar situation is likely present for low temperature $\mathrm{Si}$ segment growth with $\mathrm{Si}_{3} \mathrm{H}_{8}$. Adsorbed hydrogen atoms prevent catalyst atoms from accessing the sidewall and, in doing so, prevent the $\mathrm{Au} / \mathrm{Si}$ catalyst from solidifying. The same mechanism can explain why the catalyst appears to solidify upon reintroducing $\mathrm{Ge}_{2} \mathrm{H}_{6}$. The presence of $\mathrm{Ge}$ atoms in the trijunction region increases the hydrogen atom desorption rate $\left(\right.$ as $\left.\mathrm{H}_{2}\right)$ enough to permit atomic transport to the sidewall and identification of a low barrier site for nucleation (i.e., catalyst solidification).

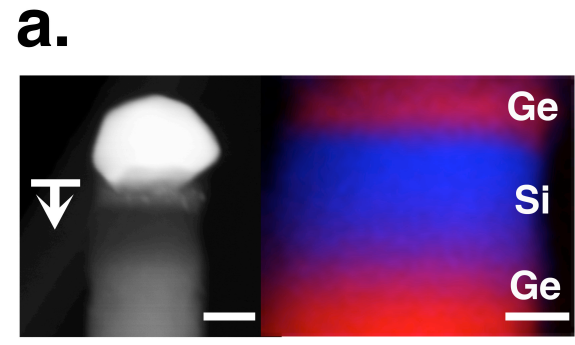

b.
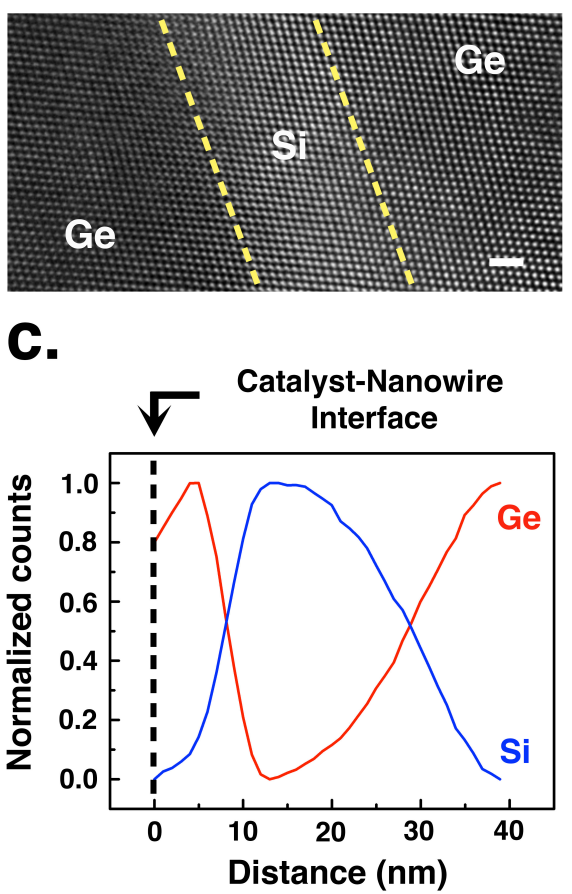

Figure 5. Compositional analysis of the $\mathrm{Ge} / \mathrm{Si} / \mathrm{Ge}$ heterointerface. (a) Representative HAADF STEM image of a $\mathrm{Ge} / \mathrm{Si} / \mathrm{Ge}$ heterostructure nanowire grown entirely at $290{ }^{\circ} \mathrm{C}$. Scale bar, $20 \mathrm{~nm}$. White line denotes the liquid-solid interface. A composite EELS map of $\mathrm{Si}$ (blue) and Ge (red) is also shown. Scale bar, $10 \mathrm{~nm}$. (b) HRTEM image of the Ge-Si-Ge region along the [1-12] zone axis. Scale bar, $1.5 \mathrm{~nm}$. (c) Axial EELS composition profiles starting at the catalyst-nanowire interface and crossing both $\mathrm{Si} / \mathrm{Ge}$ heterointerfaces.

Identification of a root cause for the temperature-dependent transition width seen in Figure 3 is still under investigation, but is likely of kinetic origin. Since the solubility of semiconductor atoms in the catalyst droplet changes only a few percent over the temperature range studied here, thermodynamics cannot fully explain the $\sim 50 \%$ change in transition width over 40 ${ }^{\circ} \mathrm{C} .{ }^{49}$ Recent work has shown that a backward reaction pathway can transfer atoms from the liquid catalyst to the gas phase, ${ }^{51-52}$ an effect that is particularly pronounced in crystallization-limited situations. The smaller transition width observed here at lower temperature (Figure 3 ) is consistent with this pathway. When crystallization is limiting, as is likely under the low temperature conditions studied here, catalyst composition will be dominated by atomic delivery/removal at the catalyst-vapor interface. In this situation, as observed here, conditions that increase the stability of gas phase product species (e.g., $\mathrm{GeH}_{\mathrm{x}}$ ), including a reduced temperature, would fa- 
vor atomic removal from the catalyst and result in a more abrupt heterointerface.

CONCLUSION. We demonstrate the low temperature growth of axial $\mathrm{Si} / \mathrm{Ge}$ heterostructures with a combination of $\mathrm{Si}_{3} \mathrm{H}_{8}$ and $\mathrm{Ge}_{2} \mathrm{H}_{6}$. Our approach prevents the catalyst perturbations that result in poor morphologies, kinks, and defects. A robust sidewall passivation is likely responsible for these observations, but additional work is required to demonstrate this directly. Our experiments show that precursor design is a powerful method to control bottom-up nanowire growth, and enable nanostructures that were previous challenging or off-limits.

\section{ASSOCIATED CONTENT}

\section{Supporting Information}

Additional figures of cross-sectional SEM images of nanowire arrays and radial EELS composition profiles, as referenced in the main text. The Supporting Information is available free of charge on the ACS Publications website.

\section{AUTHOR INFORMATION}

\section{Corresponding Author}

* To whom correspondence should be addressed: mfiller@gatech.edu and arbiol@icrea.cat

\section{Present Addresses \\ ${ }^{I}$ School of Chemical \& Biomolecular Engineering, Georgia Insti- tute of Technology, Atlanta, Georgia, 30332 United States \\ ${ }^{2}$ Catalan Institute of Nanoscience and Nanotechnology (ICN2), CSIC and The Barcelona Institute of Science and Technology (BIST), Campus UAB, Bellaterra, Barcelona, Catalonia 08193, Spain \\ ${ }_{3}^{3}$ ICREA, Pg. Lluís Companys 23, 08010 Barcelona, Catalonia, Spain}

\section{Author Contributions}

HYH grew the nanowires and collected the SEM data. HYH and MAF jointly analyzed the data and wrote the manuscript. JA and MdlM collected and analyzed the TEM data. All authors approved the final version.

\section{Notes}

The authors declare no competing financial interest.

\section{ACKNOWLEDGMENT}

MAF and HYH gratefully acknowledge the financial support of the National Science Foundation (1133563 and 1150755). HYH also thanks the Archibald McNeill Endowment at Georgia Tech and the Institute for Electronics and Nanotechnology (IEN) for additional support. JA and MdlM also acknowledge funding from Generalitat de Catalunya 2014 SGR 1638, the Spanish MINECO ICN2 Severo Ochoa Excellence Program (Grant SEV-2013-0295) and e-TNT (MAT2014-59961-C2-2-R). HYH thanks Dmitriy S. Boyuk for his support. Interactions with Dr. Jane Y. Howe were fruitful and appreciated.

\section{ABBREVIATIONS}

VLS, vapor-liquid-solid; VSS, vapor-solid-solid; $\mathrm{Si}_{3} \mathrm{H}_{8}$, trisilane; $\mathrm{Ge}_{2} \mathrm{H}_{6}$, digermane; UHV, ultra-high vacuum; SEM, scanning electron microscopy; TEM, transmission electron microscope; HRTEM, High resolution TEM; STEM, scanning TEM; FFT, Fast Fourier Transform; HAADF STEM, high angle annular dark field
STEM; GPA, geometric phase analysis; EELS, Electron energy loss spectroscopy.

\section{REFERENCES}

(1) Cui, Y.; Zhong, Z.; Wang, D.; Wang, W. U.; Lieber, C. M. High performance silicon nanowire field effect transistors. Nano Lett. 2003, 3, 149-152.

(2) Garnett, E.; Yang, P. Light trapping in silicon nanowire solar cells. Nano Lett. 2010, 10, 1082-1087.

(3) Carnevale, S. D.; Yang, J.; Phillips, P. J.; Mills, M. J.; Myers, R. C. Three-dimensional GaN/AlN nanowire heterostructures by separating nucleation and growth processes. Nano Lett. 2011, 11, 866-871.

(4) Gudiksen, M. S.; Lauhon, L. J.; Wang, J.; Smith, D. C.; Lieber, C. M. Growth of nanowire superlattice structures for nanoscale photonics and electronics. Nature 2002, 415, 617620.

(5) Ye, X.; Chen, J.; Diroll, B. T.; Murray, C. B. Tunable plasmonic coupling in self-assembled binary nanocrystal superlattices studied by correlated optical microspectrophotometry and electron microscopy. Nano Lett. 2013, 13, 1291-1297.

(6) Hyun, J. K.; Zhang, S. X.; Lauhon, L. J. Nanowire heterostructures. Annu. Rev. Mater. Res. 2013, 43, 451-479.

(7) Johansson, J.; Dick, K. A. Recent advances in semiconductor nanowire heterostructures. CrystEngComm 2011, 13, 7175-7184.

(8) Ben-Ishai, M.; Patolsky, F. From crystalline germaniumsilicon axial heterostructures to silicon nanowire-nanotubes. Nano Lett. 2012, 12, 1121-1128.

(9) Mouchet, C.; Latu-Romain, L.; Cayron, C.; Rouviere, E.; Celle, C.; Simonato, J. P. Growth of one-dimensional $\mathrm{Si} / \mathrm{SiGe}$ heterostructures by thermal CVD. Nanotechnology 2008, 19, 335603.

(10) Priante, G.; Patriarche, G.; Oehler, F.; Glas, F.; Harmand, J. C. Abrupt $\mathrm{GaP} / \mathrm{GaAs}$ interfaces in self-catalyzed nanowires. Nano Lett. 2015, 15, 6036-6041.

(11) Vainorius, N.; Lehmann, S.; Jacobsson, D.; Samuelson, L.; Dick, K. A.; Pistol, M. E. Confinement in thicknesscontrolled GaAs polytype nanodots. Nano Lett. 2015, 15, 2652-2656.

(12) Amato, M.; Palummo, M.; Rurali, R.; Ossicini, S. Silicon-germanium nanowires: chemistry and physics in play, from basic principles to advanced applications. Chem. Rev. 2014, 114, 1371-1412.

(13) Huang, Y.; Duan, X.; Cui, Y.; Lauhon, L. J.; Kim, K. H.; Lieber, C. M. Logic gates and computation from assembled nanowire building blocks. Science 2001, 294, 1313-1317.

(14) Le, S. T.; Jannaty, P.; Luo, X.; Zaslavsky, A.; Perea, D. E.; Dayeh, S. A.; Picraux, S. T. Axial SiGe heteronanowire tunneling field-effect transistors. Nano Lett. 2012, 12, 58505855 .

(15) Björk, M. T.; Ohlsson, B. J.; Thelander, C.; Persson, A. I.; Deppert, K.; Wallenberg, L. R.; Samuelson, L. Nanowire resonant tunneling diodes. Appl. Phys. Lett. 2002, 81, 44584460.

(16) Amato, M.; Palummo, M.; Ossicini, S.; Rurali, R. SiGe nanowires for thermoelectrics applications. In Nanoscale Thermoelectrics, Lecture Notes in Nanoscale Science and 
Technology, Wang, X.; Wang, Z. M., Eds. Springer International Publishing: Switzerland, 2014; Vol. 16, pp 497-515.

(17) Li, D.; Wu, Y.; Fan, R.; Yang, P.; Majumdar, A. Thermal conductivity of $\mathrm{Si} / \mathrm{SiGe}$ superlattice nanowires. Appl. Phys. Lett. 2003, 83, 3186-3188.

(18) Hu, M.; Poulikakos, D. Si/Ge superlattice nanowires with ultralow thermal conductivity. Nano Lett. 2012, 12, 54875494.

(19) Geaney, H.; Mullane, E.; Ramasse, Q. M.; Ryan, K. M. Atomically abrupt silicon-germanium axial heterostructure nanowires synthesized in a solvent vapor growth system. Nano Lett. 2013, 13, 1675-1680.

(20) Li, C. B.; Usami, K.; Mizuta, H.; Oda, S. Growth of Ge-Si nanowire heterostructures via chemical vapor deposition. Thin Solid Films 2011, 519, 4174-4176.

(21) Eisenhawer, B.; Sivakov, V.; Berger, A.; Christiansen, $\mathrm{S}$. Growth of axial $\mathrm{SiGe}$ heterostructures in nanowires using pulsed laser deposition. Nanotechnology 2011, 22 (30), 305604.

(22) Dayeh, S. A.; Wang, J.; Li, N.; Huang, J. Y.; Gin, A. V.; Picraux, S. T. Growth, defect formation, and morphology control of germanium-silicon semiconductor nanowire heterostructures. Nano Lett. 2011, 11, 4200-4206.

(23) Flynn, G.; Ramasse, Q. M.; Ryan, K. M. Solvent vapor growth of axial heterostructure nanowires with multiple alternating segments of silicon and germanium. Nano Lett. 2016, 16, 374-380.

(24) Clark, T. E.; Nimmatoori, P.; Lew, K. K.; Pan, L.; Redwing, J. M.; Dickey, E. C. Diameter dependent growth rate and interfacial abruptness in vapor-liquid-solid $\mathrm{Si} / \mathrm{Si}_{1-\mathrm{x}} \mathrm{Ge}_{\mathrm{x}}$ heterostructure nanowires. Nano Lett. 2008, 8, 1246-1252.

(25) Wu, Y.; Fan, R.; Yang, P. Block-by-Block Growth of single-crystalline $\mathrm{Si} / \mathrm{SiGe}$ superlattice nanowires. Nano Lett. 2002, 2, 83-86.

(26) Chang, H. Y.; Tsybeskov, L.; Sharma, S.; Kamins, T. I.; Wu, X.; Lockwood, D. J. Photoluminescence and Raman scattering in axial $\mathrm{Si} / \mathrm{Ge}$ nanowire heterojunctions. Appl. Phys. Lett. 2009, 95, 133120.

(27) Wang, X.; Tsybeskov, L.; Kamins, T. I.; Wu, X.; Lockwood, D. J. Structural and optical properties of axial silicongermanium nanowire heterojunctions. J. Appl. Phys. 2015, $118,234301$.

(28) D’Evelyn, M. P.; Yang, Y. L.; Cohen, S. M. Adsorption, desorption, and decomposition of $\mathrm{HCl}$ and $\mathrm{HBr}$ on $\mathrm{Ge}(100)$ : Competitive pairing and near-first-order desorption kinetics. $J$. Chem. Phys. 1994, 101, 2463-2475.

(29) Jackman, R. B.; Ebert, H.; Foord, J. S. Reaction mechanisms for the photon-enhanced etching of Semiconductors an investigation of the UV-stimulated interaction of chlorine with Si(100). Surf. Sci. 1986, 176, 183-192.

(30) Jackman, R. B.; Price, R. J.; Foord, J. S. Semiconductor surface etching by halogens - Fundamental steps. Appl. Surf. Sci. 1989, 36, 296-312.

(31) Chou, Y. C.; Wen, C. Y.; Reuter, M. C.; Su, D.; Stach, E. A.; Ross, F. M. Controlling the growth of $\mathrm{Si} / \mathrm{Ge}$ nanowires and heterojunctions using silver-gold alloy catalysts. $A C S$ nano 2012, 6, 6407-6415.

(32) Wen, C. Y.; Reuter, M. C.; Bruley, J.; Tersoff, J.; Kodambaka, S.; Stach, E. A.; Ross, F. M. Formation of composi- tionally abrupt axial heterojunctions in silicon-germanium nanowires. Science 2009, 326, 1247-1250.

(33) Kumata, K.; Itoh, U.; Toyoshima, Y.; Tanaka, N.; Anzai, H.; Matsuda, A. Photochemical vapor deposition of hydrogenated amorphous silicon films from disilane and trisilane using a low pressure mercury lamp. Appl. Phys. Lett. 1986, 48, 1380-1382.

(34) Kim, H.; Spila, T.; Greene, J. E. Si(113) hydrogen desorption kinetics: a temperature programmed desorption study. Surf. Sci. 2001, 490, L602-L608.

(35) Oura, K.; Lifshits, V. G.; Saranin, A. A.; Zotov, A. V.; Katayama, M. Hydrogen interaction with clean and modified silicon surfaces. Surf. Sci. Rep. 1999, 35, 1-69.

(36) Kim, H.; Vailionis, A.; Cahill, D. G.; Greene, J. E. Ge(011)-c(8×10) surface structure and hydrogen desorption pathways: a temperature-programmed desorption and scanning tunneling microscopy study. Surf. Sci. 2000, 457, 337-344.

(37) Lee, J. Y.; Maeng, J. Y.; Kim, A.; Cho, Y. E.; Kim, S. Kinetics of $\mathrm{H}_{2}\left(\mathrm{D}_{2}\right)$ desorption from a $\mathrm{Ge}(100)-2 \times 1: \mathrm{H}$ (D) surface studied using scanning tunneling microscopy and temperature programmed desorption. J. Chem. Phys. 2003, 118 , 1929-1936.

(38) Shin, N.; Filler, M. A. Controlling silicon nanowire growth direction via surface chemistry. Nano Lett. 2012, 12, 2865-2870.

(39) Sivaram, S. V.; Shin, N.; Chou, L. W.; Filler, M. A. Direct observation of transient surface species during Ge nanowire growth and their influence on growth stability. J. Am. Chem. Soc. 2015, 137, 9861-9869.

(40) Fontcuberta i Morral, A.; Arbiol, J.; Prades, J. D.; Cirera, A.; Morante, J. R. Synthesis of silicon nanowires with wurtzite crystalline structure by using standard chemical vapor deposition. Adv. Mater. 2007, 19, 1347-1351.

(41) Arbiol, J.; Estrade, S.; Prades, J. D.; Cirera, A.; Furtmayr, F.; Stark, C.; Laufer, A.; Stutzmann, M.; Eickhoff, M.; Gass, M. H.; Bleloch, A. L.; Peiro, F.; Morante, J. R. Triple-twin domains in $\mathrm{Mg}$ doped $\mathrm{GaN}$ wurtzite nanowires: structural and electronic properties of this zinc-blende-like stacking. Nanotechnology 2009, 20, 145704.

(42) Hÿtch, M. J.; Snoeck, E.; Kilaas, R. Quantitative measurement of displacement and strain fields from HREM micrographs. Ultramicroscopy 1998, 74, 131-146.

(43) Sivaram, S. V.; Hui, H. Y.; de la Mata, M.; Arbiol, J.; Filler, M. A. Surface hydrogen enables subeutectic vaporliquid-solid semiconductor nanowire growth. Nano Lett. 2016, 16, 6717-6723.

(44) de la Mata, M.; Leturcq, R.; Plissard, S. R.; Rolland, C.; Magen, C.; Arbiol, J.; Caroff, P. Twin-Induced InSb nanosails: A convenient high mobility quantum system. Nano Lett. 2016, 16, 825-833.

(45) de la Mata, M.; Magen, C.; Caroff, P.; Arbiol, J. Atomic scale strain relaxation in axial semiconductor III-V nanowire heterostructures. Nano Lett. 2014, 14, 6614-6620.

(46) Dick, K. A.; Bolinsson, J.; Borg, B. M.; Johansson, J. Controlling the abruptness of axial heterojunctions in III-V nanowires: beyond the reservoir effect. Nano Lett. 2012, 12, 3200-3206. 
(47) Li, N.; Tan, T. Y.; Gösele, U. Transition region width of nanowire hetero- and pn-junctions grown using vapor-liquidsolid processes. Appl. Phys. A 2008, 90, 591-596.

(48) Dayeh, S. A.; Picraux, S. T. Direct observation of nanoscale size effects in Ge semiconductor nanowire growth. Nano Lett. 2010, 10, 4032-4039.

(49) Kodambaka, S.; Tersoff, J.; Reuter, M. C.; Ross, F. M. Germanium nanowire growth below the eutectic temperature. Science 2007, 316, 729-732.

(50) Westwater, J.; Gosain, D. P.; Tomiya, S.; Usui, S.; Ruda, H. Growth of silicon nanowires via gold/silane vaporliquid-solid reaction. J. Vac. Sci. Technol. B 1997, 15, 554557.

(51) Hui, H. Y.; Filler, M. A. Solid-liquid-vapor etching of semiconductor nanowires. Nano Lett. 2015, 15, 6939-6945.

(52) Pinion, C. W.; Nenon, D. P.; Christesen, J. D.; Cahoon, J. F. Identifying crystallization- and incorporation-limited regimes during vapor-liquid-solid growth of Si nanowires. ACS Nano 2014, 8, 6081-6088. 
TOC GRAPHIC

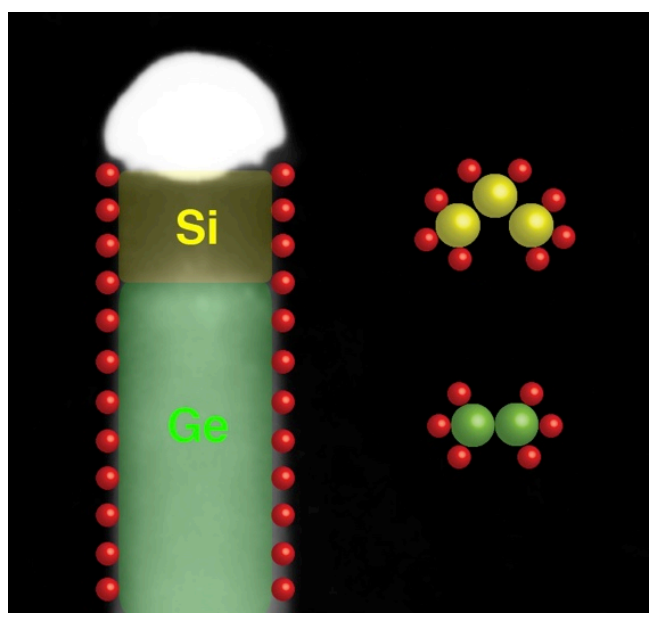

